\title{
Impaired Attention and Synaptic Senescence of the Prefrontal Cortex Involves Redox Regulation of NMDA Receptors
}

\author{
Michael Guidi, ${ }^{*}$ Ashok Kumar, ${ }^{*}$ and Thomas C. Foster \\ Department of Neuroscience, McKnight Brain Institute, University of Florida, Gainesville, Florida 32610
}

\begin{abstract}
Young (3-6 months) and middle-age (10-14 months) rats were trained on the five-choice serial reaction time task. Attention and executive function deficits were apparent in middle-age animals observed as a decrease in choice accuracy, increase in omissions, and increased response latency. The behavioral differences were not due to alterations in sensorimotor function or a diminished motivational state. Electrophysiological characterization of synaptic transmission in slices from the mPFC indicated an age-related decrease in glutamatergic transmission. In particular, a robust decrease in $N$-methyl-D-aspartate receptor (NMDAR)-mediated synaptic responses in the mPFC was correlated with several measures of attention. The decrease in NMDAR function was due in part to an altered redox state as bath application of the reducing agent, dithiothreitol, increased the NMDAR component of the synaptic response to a greater extent in middle-age animals. Together with previous work indicating that redox state mediates senescent physiology in the hippocampus, the results indicate that redox changes contribute to senescent synaptic function in vulnerable brain regions involved in age-related cognitive decline.
\end{abstract}

Key words: aging; attention; executive function; NMDA receptor; prefrontal cortex; redox state

\section{Introduction}

Humans are living longer today than at any other time in history, and attention is increasingly focused on problems that arise from improved longevity, including a progressive cognitive weakening over the course of aging. Early indications of cognitive decline included impairments in episodic memory and executive function, which emerge in middle-age, and suggest enhanced vulnerability of the specific neural circuits that underlie these processes (Silver et al., 2009; Alexander et al., 2012; Bizon et al., 2012; Foster, 2012a; Samson and Barnes, 2013).

Executive function is a comprehensive term used to describe a collection of cognitive abilities including attention, problem solving, set-shifting, and working memory. An age-related impairment in executive function in humans is commonly observed as an increase in the latency of decision making, reduced cognitive flexibility, attentional impairments, and decreased working memory capacity (Babcock and Salthouse, 1990; Robbins et al., 1998; Gazzaley et al., 2005; Staub et al., 2014; Zavagnin et al., 2014). Similar to humans, rodent models of cognitive aging exhibit

\footnotetext{
Received Aug. 22, 2014; revised Dec. 23, 2014; accepted Jan. 21, 2015.

Author contributions: M.G., A.K., and T.C.F. designed research; M.G. and A.K. performed research; M.G., A.K., and T.C.F. analyzed data; M.G., A.K., and T.C.F. wrote the paper.

This work is supported by National Institute of Aging grants R01AG037984 and R37AG036800 and the Evelyn F. McKnight Brain Research Foundation.

The authors declare no competing financial interests.

*M.G. and A.K. contributed equally to this work.

Correspondence should be addressed to either Thomas C. Foster or Ashok Kumar, Department of Neuroscience,

McKnight Brain Institute, University of Florida, P.0. Box 100244, Gainesville, FL 32610-0244. E-mail: Foster1@ufl.edu or Kash@ufl.edu.

DOI:10.1523/JNEUROSCI.3523-14.2015

Copyright $\odot 2015$ the authors $\quad 0270-6474 / 15 / 353966-12 \$ 15.00 / 0$
}

attentional deficits (Moore et al., 1992; Jones et al., 1995; Muir et al., 1999; Grottick and Higgins, 2002), impaired cognitive flexibility (Barense et al., 2002; Nicolle and Baxter, 2003), and decreased working memory (Beas et al., 2013; Bañuelos et al., 2014).

The prefrontal cortex (PFC) is intimately involved in mediating executive function in humans. Similarly, in rodents the cognitive processes that fall under the domain of executive function involve the medial PFC (mPFC) (Muir et al., 1996; Birrell and Brown, 2000; Chudasama et al., 2003; Lee and Kesner, 2003; Stefani et al., 2003) and the senescence of mPFC circuits may underlie the decline in executive function. Studies that employ $\mathrm{N}$-methyl-D-aspartate receptor (NMDAR) antagonists, demonstrate a role for NMDARs in executive function (Stefani and Moghaddam, 2005; Cui et al., 2011; Dalton et al., 2011; Arnsten et al., 2012; Carli and Invernizzi, 2014). Moreover, the decline in executive function during aging is associated with a loss of dendritic spines in the PFC, particularly thin spines that are thought to be involved in NMDAR-mediated synaptic plasticity (Bourne and Harris, 2007; Morrison and Baxter, 2012; Samson and Barnes, 2013). However, it is unclear if NMDAR function in the PFC declines with age and whether altered NMDAR function is associated with the emergence of impaired executive function.

Our recent work indicates that another major category of agerelated cognitive decline, impaired episodic memory, emerges in middle-age and is associated with a decrease in hippocampal NMDAR function due to an oxidized redox environment (Bodhinathan et al., 2010b; Lee et al., 2012, 2014; Kumar and Foster, 2013). Therefore, the current study was designed to determine whether a decrease in NMDAR function in the mPFC could contribute to the emergence of impaired executive function and whether the redox-mediated decrease in NMDAR function dur- 
ing aging is limited to the hippocampus. In confirmation of previous research (Jones et al., 1995; Muir et al., 1999; Harati et al., 2011), we observed a deficit in attention that was apparent in middle-age animals. In addition, middle-age animals exhibited changes in glutamatergic transmission in the $\mathrm{MPFC}$, which correlated with measures of attention. A decrease in NMDAR function was due in part to an oxidized redox state. The results indicate that brain regions linked to cognitive decline are vulnerable to a redox-mediated decrease in NMDAR function, which emerges in middle-age.

\section{Materials and Methods}

\section{Subjects}

Young (3-6 months, $n=14)$ and middle-age (10-14 months, $n=23)$ male Fisher 344 rats were obtained from the National Institute on Aging colony (Taconic) through the University of Florida Animal Care and Service facility. Animals were paired, housed (two per cage), and maintained on a $12 / 12 \mathrm{~h}$ reverse light cycle with ad libitum access to water. All procedures involving animal subjects were reviewed and approved by the Institutional Animal Care and Use Committee and were in accordance with guidelines established by the U.S. Public Health Service Policy on Humane Care and Use of Laboratory Animals.

\section{Behavioral tests}

Five-choice serial reaction time task. Rats were food restricted to $85 \%$ of their free-feeding weight and were maintained at this weight throughout the behavioral experiments. Rats were trained on the five-choice serial reaction time task (5-CSRTT; Carli et al., 1983; Muir et al., 1999; Dalley et al., 2001, 2004; Passetti et al., 2002; Chudasama et al., 2003; Harati et al., 2011). This task requires rats to attend to and detect brief flashes of light presented pseudorandomly in one of five apertures while making a corresponding nose poke response to obtain a food reward.

Apparatus. Testing was conducted in two identical standard rat-testing chambers $(30.5 \times 25.4 \times 30.5 \mathrm{~cm}$; Coulbourn Instruments $)$ with metal front and back walls, and transparent Plexiglas sidewalls. The floor was composed of a stainless steel wire mesh grid that is typically implemented for nonshock behavioral experiments. Each testing chamber was housed in a sound-attenuating cubicle, illuminated by a $3 \mathrm{~W}$ house light. Each cage was equipped with a recessed food pellet delivery trough, located $\sim 2$ $\mathrm{cm}$ above the grid floor, in the center of the back wall. Each trough was fitted with a photobeam sensor to detect head entries and food reward pellet retrieval (45 mg grain based; Test Diet). A $1.12 \mathrm{~W}$ light was used to illuminate the food trough. Five evenly spaced circular apertures, each containing six tricolored cue LED lights and a photobeam sensor, were set into the front, curved metal wall $2 \mathrm{~cm}$ above the grid floor. The behavioral experiments were controlled through a computer interfaced with the testing chambers, and equipped with Graphic State v3.03 software (Coulbourn Instruments).

Training procedures. Each rat was tested in the same chamber throughout the experiment. For the first phase of training, rats were placed in the conditioning chambers for $15 \mathrm{~min}$ with the house light on and the food magazine filled with 10 food pellets to familiarize the animals with the training box. In the second phase, rats received two $30 \mathrm{~min}$ food magazine training sessions, during which 100 food pellets were delivered using a variable time schedule (mean $=60 \mathrm{~s}$ ). In the third phase of training, all nose poke openings were accessible to the animal and were illuminated for the entire $30 \mathrm{~min}$ session. Each time the rat placed its nose into the illuminated hole, a food pellet was delivered to the animal. This training was continued until the rats made at least 50 nose pokes during a single session. At this point the animals were considered to have acquired a nose poke response for a food reward, and the rats were then trained to nose poke in response to a brief $30 \mathrm{~s}$ visual stimulus that was presented pseudorandomly in one of the five possible locations. Once the animals completed 50 trials for two consecutive training sessions, they then progressed to training on the next, shorter cue duration interval. The cue durations used for training included $0.25,0.5,2.5,10$, and $30 \mathrm{~s}$.
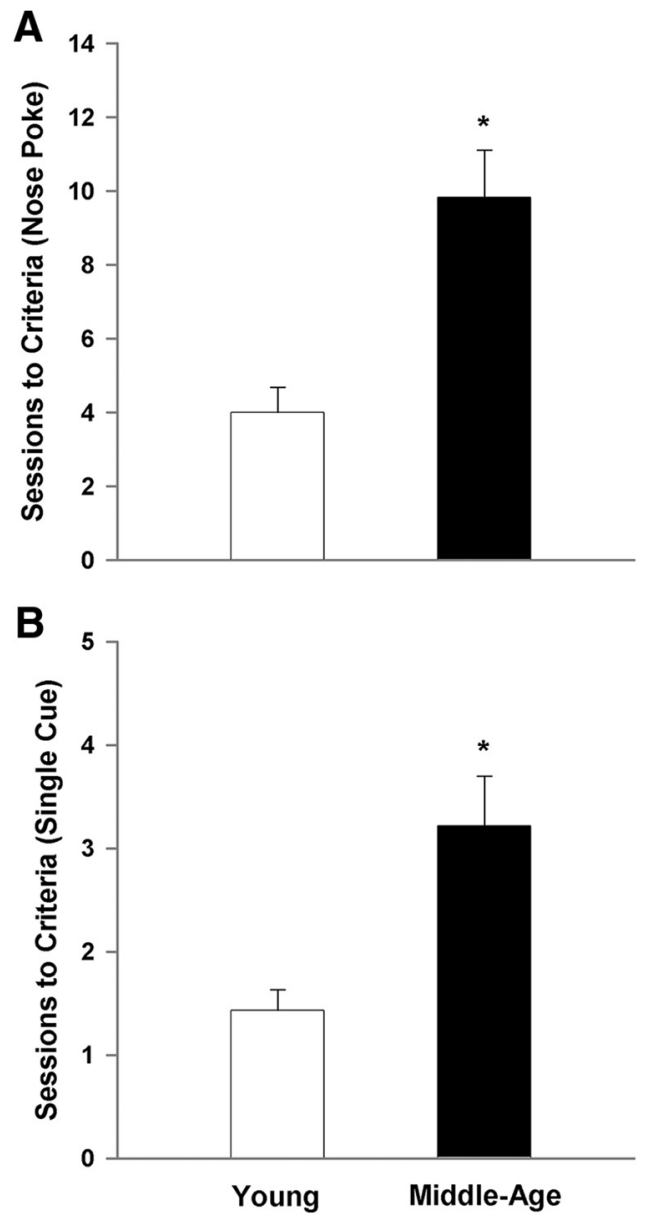

Figure 1. Acquisition of the behaviors required for the 5-CSRTT is impaired in middle-age rats. For this and all subsequent figures, measures for the young are illustrated in the open bars or symbols and the filled bars or symbols represent measures for middle-age animals. The criterion for acquisition was set at completion of 50 trials in a single session. $A$, Middle-age rats require significantly more training sessions to learn the association of a nose poke response to any of the illuminated openings with receipt of a food reward. $\boldsymbol{B}$, Middle-age rats also require significantly more training sessions to learn the valid nose poke/food reward pairing when the visual stimulus is presented in only one aperture per trial. Asterisk indicates an age difference $(p<0.05)$.

At the beginning of each training/test session, the cage house light was illuminated and a single food pellet was delivered to the magazine without requiring a nose poke. The first trial was initiated when the rat collected the food pellet from the food magazine. After a fixed delay (intertrial interval, ITI $=5 \mathrm{~s}$ ), one of the five holes was illuminated for a given stimulus duration. The rat was rewarded with a food pellet if it made a response to the illuminated hole or a response in that particular hole during a fixed period of time after the light stimulus was turned off (the limited hole hold period $=5 \mathrm{~s}$ ). This response was recorded as a correct response. The next trial was initiated when the rat retrieved the food pellet. Responses in a nonilluminated hole during the signal period (i.e., the stimulus duration + the limited hole hold period) were recorded as incorrect responses, and failures to respond within the limited hold period were recorded as omissions and resulted in a $5 \mathrm{~s}$ period of darkness (time-out). A response in any hole during the ITI was recorded as a premature response and was followed by a time-out period. After a time-out, the next trial was initiated when the rat placed its nose into the empty, lit food magazine. The daily testing sessions consisted either of 100 trials or was terminated after 30 min of testing. During a 100 trial session, the light stimulus was presented an equal number of times in each of the five aperture positions. Rats were trained until a criteria of two consecutive sessions with 50 or more correct responses was achieved at a given stimulus duration. 
Variable cue duration paradigm. Upon the completion of training, rats were tested on the variable cue duration paradigm of the 5-CSRTT. This paradigm was designed to allow for a within-session evaluation of attention and executive function with the optical stimuli presented at various durations $(0.25,0.5,2.5,10$, and $30 \mathrm{~s})$ during a single testing session. This system allows for an assessment in the animals' attentional abilities at various levels of attentional demand. In this paradigm, the presentation of the cue stimuli was randomized by both spatial location and temporal duration.

Variable cue intensity paradigm. To assess any potential confounds in the rodents' ability to visually perceive and discriminate the visual cues presented during the 5-CSRTT, the animals were tested on the variable cue intensity paradigm. This paradigm was designed to evaluate the animals' performance when the illuminant's optical intensity is varied at differing levels, or lumens, during a single testing session. The presentation of the cue stimulus was therefore randomized by spatial location and optical intensity (full intensity or $1 / 3$ intensity), while the temporal duration of the cue was kept constant at $0.5 \mathrm{~s}$.

\section{Electrophysiological experiments}

PFC slice preparation. The protocol for preparation of PFC slices for electrophysiological studies was modified from standardized protocols in our lab (Bodhinathan et al., 2010b; Kumar and Foster, 2013, 2014; Lee et al., 2014). Animals were deeply anesthetized using isoflurane (Webster) and decapitated with a guillotine (myNeuroLab). The brain was rapidly removed and transferred into a beaker containing ice-cold artificial cerebrospinal fluid (aCSF). The PFC was dissected and one hemisphere was frozen at $-80^{\circ} \mathrm{C}$ for protein analysis. The contralateral PFC was blocked and four to six coronal slices $(\sim 400 \mu \mathrm{m})$ were cut through the mPFC $(+5.0$ to +2.5 anterior to bregma; Paxinos and Watson, 1986) using a tissue chopper (Mickle Laboratory Engineering). The freshly cut slices were incubated in a holding chamber (at room temperature) with aCSF containing the following (in $\mathrm{mM}$ ): 124 $\mathrm{NaCl}, 2 \mathrm{KCl}, 1.25 \mathrm{KH}_{2} \mathrm{PO}_{4}, 2 \mathrm{MgSO}_{4}, 2 \mathrm{CaCl}_{2}, 26$ $\mathrm{NaHCO}_{3}$, and 10 D-glucose. Slices were transferred to a standard interface recording chamber (Warner Instrument) at least 30 min before recording. The chamber was continuously perfused with oxygenated aCSF $\left(95 \%-\mathrm{O}_{2}\right.$ and $\left.5 \%-\mathrm{CO}_{2}\right)$ at the rate of $2 \mathrm{ml} / \mathrm{min}$ and the temperature was maintained at $30 \pm 0.5^{\circ} \mathrm{C}$ using the TC-324B temperature controller (Warner Instrument). The $\mathrm{pH}$ of the aCSF was maintained at 7.4.

Extracellular field potential recordings. Field EPSPs (fEPSPs) were recorded using a glass micropipette electrode filled with aCSF. The glass micropipettes were pulled from thin-walled borosilicate capillary glass using a Flaming/Brown horizontal micropipette puller (Sutter Instruments), and the electrode resistances ranged from 4 to $6 \mathrm{M} \Omega$. The pipette was localized to layer $2 / 3$ of the prelimbic region of the mPFC (Paxinos and Watson, 1986). A concentric bipolar stimulating electrode (FHC) was localized to layer 4/5. Diphasic stimulus pulses (100 $\mu$ s; SD9 Stimulator, Grass Instrument) were delivered to the layer $4 / 5$ of the $\mathrm{mPFC}(0.033 \mathrm{~Hz})$ to evoke fEPSPs. The signals were sampled at a frequency of $20 \mathrm{kHz}$, amplified, and filtered between $1 \mathrm{~Hz}$ and $1 \mathrm{kHz}$ using Axoclamp-2A (Molecular Devices) and a differential AC amplifier (A-M Systems). Field potential data were stored on a computer hard drive (Dell) for off-line analysis. A separate output from the differential AC amplifier was fed into an oscilloscope (Tektronix 2214) for real-time visualization of the signals. To measure the amplitude of the fEPSP, two cursors were
Table 1. Antibodies employed for Western blots

\begin{tabular}{llll}
\hline Antibody & Concentration & Host & Vendor \\
\hline GluN1 & $1: 2000$ & Rabbit & Cell Signaling Technology \\
GluN2A & $1: 1000$ & Rabbit & Millipore \\
GluN2B & $1: 1000$ & Mouse & Millipore \\
PSD-95 & $1: 4000$ & Rabbit & Cell Signaling Technology \\
GAPDH & $1: 12000$ & Mouse & EnCor \\
\hline
\end{tabular}
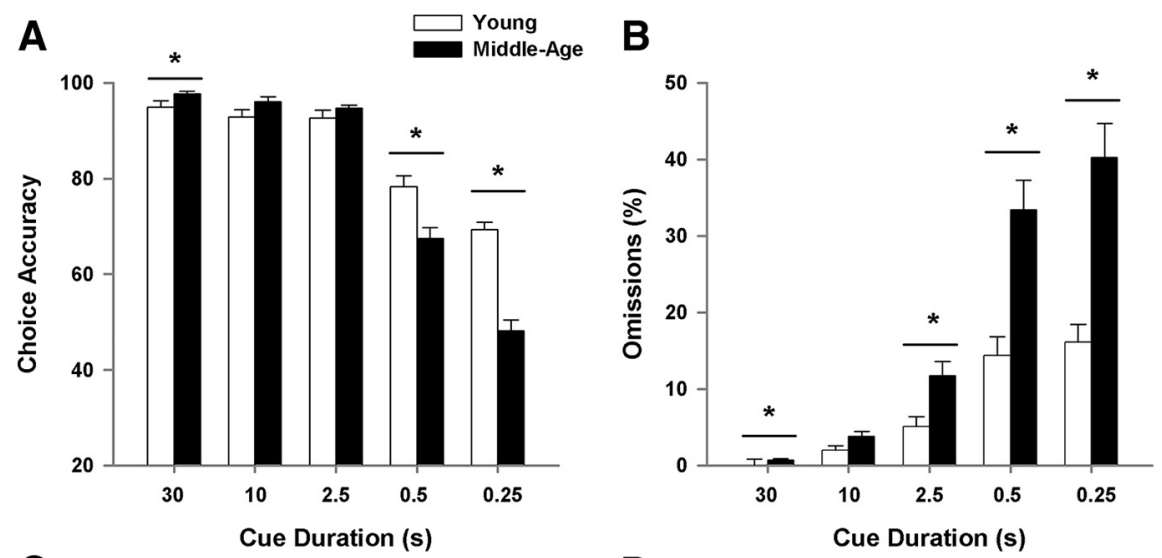

D

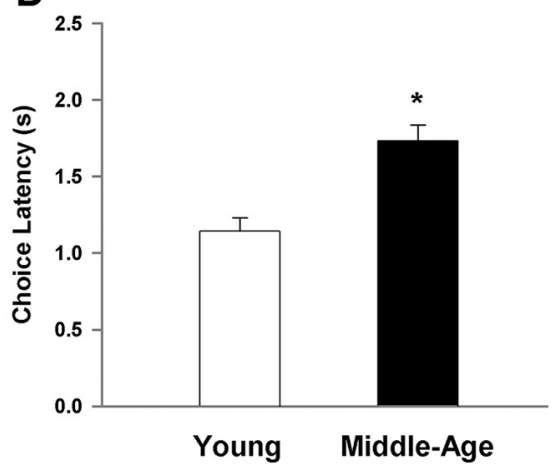

Figure 2. Performance in the 5-CSRTT is impaired in middle-age rats for the shorter cue durations. $A$, Choice accuracy decreases 列 across session for each animal and bars represent the means ( + SEM) for the animals in each age group. Asterisk signifies a significant difference from young $(p<0.05)$.

placed to encompass the entire waveform. A SciWorks computer algorithm (Datawave Technologies) was used to compute the maximum amplitude $(\mathrm{mV})$ of the fEPSP at the peak of the waveform as well as the slope of the descending response. To measure the slope of the fEPSP, two cursors were placed around the initial descending phase of the waveform and the maximum slope $(\mathrm{mV} / \mathrm{ms})$ of the EPSP was determined by a computer algorithm that found the maximum change across all sets of 20 consecutively recorded points between the two cursors. Input-output curves for the total fEPSP were constructed for increasing stimulation intensities. To assess the paired-pulse ratio, pulse pairs were delivered through a single stimulating electrode at various interpulse intervals (50, 100,200 , and $300 \mathrm{~ms}$ ). The first pulse was set to elicit $50 \%$ of the maximal fEPSP, as observed with the input-output curve. Five paired responses were recorded for each interpulse interval.

Isolation of NMDAR-mediated EPSP. Following collection of the total synaptic response the NMDAR-mediated fEPSPs (NMDAR-fEPSPs) were isolated and recorded, as previously reported for hippocampus in our lab (Bodhinathan et al., 2010b; Kumar and Foster, 2013; Lee et al., 2014). To obtain the NMDAR-fEPSPs, PFC slices were incubated in aCSF containing a low concentration of extracellular $\mathrm{Mg}^{2+}(0.5 \mathrm{~mm})$, 6,7-dinitroquinoxaline-2,3-dione (DNQX;30 $\mu \mathrm{M}$; Sigma), and picro- 
toxin (PTX; $10 \mu \mathrm{M}$; Tocris Bioscience). Input-output curves for the NMDAR-mediated fEPSP were constructed for increasing stimulation intensities. In some cases, pharmacological isolation of the NMDARmediated fEPSP was confirmed by the application of the NMDAR antagonist AP-5 (100 $\mu \mathrm{M})$. DNQX was initially dissolved in dimethyl sulfoxide (DMSO; Sigma) and diluted in aCSF to a final DMSO concentration of $<0.01 \%$ and to a final DNQX concentration of $30 \mu \mathrm{M}$. PTX was initially dissolved in ethanol and diluted in aCSF to a final ethanol concentration of $0.0001 \%$ and to final PTX concentrations of $10 \mu \mathrm{M}$. Dithiolthreitol (DTT;0.5 mM; Sigma) was directly dissolved in aCSF.

Analysis of reducing agent on NMDAR-EPSP. To examine the effects of the reducing agent, DTT, the baseline response was set at $\sim 50 \%$ of the maximum and responses were collected for at least $10 \mathrm{~min}$ before and $60-70 \mathrm{~min}$ after drug application. The DTT dose $(0.5 \mathrm{~mm})$ was selected due to previous studies that show this dose is within a range that can increase NMDAR responses specifically in aged animals, and in young animals under oxidizing conditions, and yet is below a dose that impairs enzyme activity (Tang and Aizenman, 1993a, b; Bodhinathan et al., 2010b; Kumar and Foster, 2013; Lee et al., 2014).

\section{Western blot analysis}

The $\mathrm{mPFC}$ was blocked into $\sim 1-2 \mathrm{~mm}$ slabs anterior to the genu of the corpus callosum and the prelimbic region of the mPFC (Paxinos and Watson, 1986) was dissected out. Tissues were sonicated and lysed in RIPA buffer (Thermo Scientific) supplemented with phosphatase inhibitors, protease inhibitors, and EDTA (Thermo Scientific) and centrifuged at $20,000 \times g$ for $30 \mathrm{~min}$ at $4^{\circ} \mathrm{C}$. Protein concentrations were first determined using the bicinchoninic acid (Pierce) method for the colorimetric detection and quantitation of total protein. Kaleidoscope protein standards (Bio-Rad) and samples (20-30 $\mu \mathrm{g} / \mathrm{lane})$ were loaded on $4-15 \%$ SDS-PAGE gradient gels (Bio-Rad) and run for $\sim 1 \mathrm{~h}$ at $115 \mathrm{~V}$. The proteins were then transferred to a PDVF membrane (GE Healthcare) overnight at $45 \mathrm{~V} / 4^{\circ} \mathrm{C}$. Following electrotransfer, blots were stained with Ponceau $\mathrm{S}$ and examined for transfer quality. Blots were washed for $5 \mathrm{~min}$ in TBST and subsequently blocked for $1 \mathrm{~h}$ with $5 \%$ nonfat dry milk (in TBST). Primary antibodies were applied to blots and allowed to incubate overnight at $4^{\circ} \mathrm{C}$ (Table 1). Following incubation, blots were washed three times with TBST for $5 \mathrm{~min}$, and secondary antibodies were applied for $1 \mathrm{~h}$ at room temperature. Blots were then developed using the ECL Plus Western blot Detection Kit (GE Healthcare) on BioMax film (Kodak). Film images were digitally scanned using the Model 6500 scanner (Bio-Rad) and densitometry was determined using Image Studio Lite software (LI-COR Biosciences).

\section{Statistical analysis}

ANOVAs and regression analyses were performed using StatView 5.0 (SAS Institute). Fisher's protected least significant difference post hoc tests, with $p$ set at 0.05 , were used to localize differences. Acquisition of nose poke behavior was recorded as the number of sessions required for the animal to complete 50 trials in a single session. For the variable cue duration or intensity studies, measures of attention were assessed in terms of choice accuracy in detecting the light stimulus, expressed as a percentage of the total number of correct and incorrect trials (correct responses/total number of correct and incorrect responses), the number of omissions expressed as a percentage (number of omissions/total number of correct, incorrect, and omitted responses), and the latency to respond to the cue. Inhibitory response control was measured as the percentage of premature responses (number of premature responses/ total number of trials). Motor function was measured as the latency to respond to collect the reward. For the cue duration and cue intensity tasks, a main effect of training session was not observed for any of the behavioral measures; therefore, behavioral measures were averaged across training days for each animal and the averages were used for figures and correlation of behavioral measures with electrophysiological and Western blot measures. For electrophysiological measures, in many cases, responses were recorded from multiple slices. The data were averaged across slices for the same animal and the data for each animal was used for statistical analyses. For regression analyses, comparisons were first conducted using all animals. For significant regressions, a subsequent regression was limited to middle-age animals.
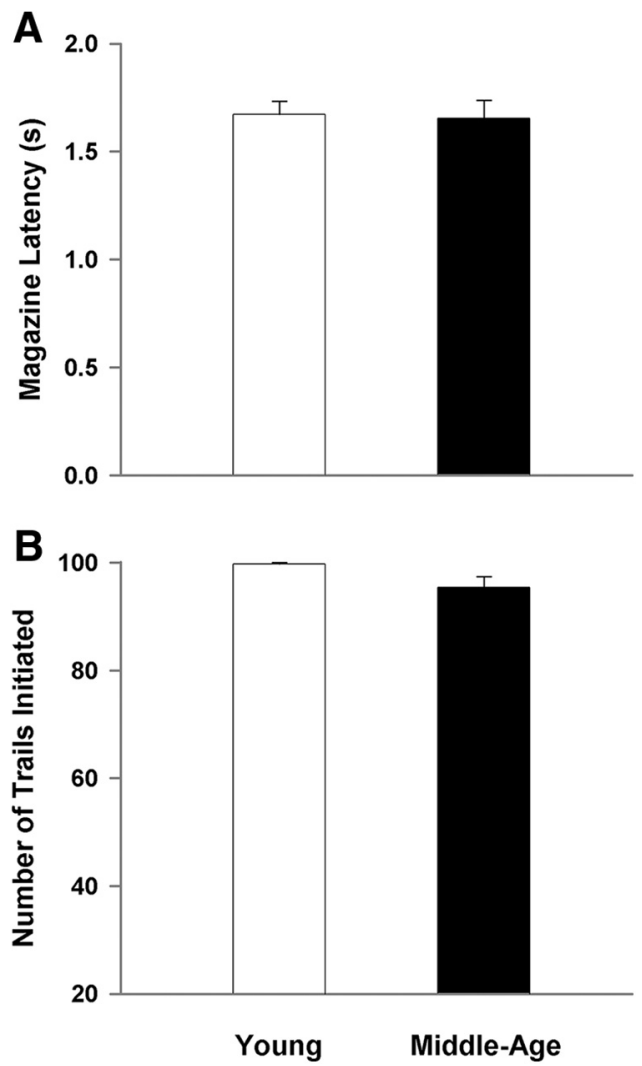

Figure 3. Differences in performance are not due to motor or motivational differences. $\boldsymbol{A}$, No age difference was observed for the measure of magazine latency, suggesting unimpaired motor function. $\boldsymbol{B}$, The average number of initiated trials is similar between the young and middle-age cohorts, indicating differences in performance are not due to lack of motivation to complete the task.

\section{Results}

Task acquisition

The data for task acquisition in 5-CSRTT are illustrated in Figure 1 and show the average number of training sessions required to complete at least 50 trials in one session. There was a significant main effect of age $\left(F_{(1,35)}=11.40, p<0.005\right)$ for the average number of sessions required to acquire nose poke training (i.e., learn to associate a nose poke response in any illuminated aperture to the receipt of a food reward). Furthermore, there was a main effect of age $\left(F_{(1,35)}=7.90, p<0.01\right)$ for the number of sessions needed to complete at least 50 trials in one session during training at the initial $30 \mathrm{~s}$ cue duration (Fig. 1B). Despite a slower rate of acquisition for the initial $30 \mathrm{~s}$ duration, all rats reached a criterion of 50 or more completed trials within three sessions for the other training durations (mean of $<1.5$ sessions for each age group at each duration) and ANOVAs for the remaining cue durations indicated no age difference in the number of trials to reach criterion.

\section{Performance in the variable cue duration paradigm}

A repeated-measures ANOVA examined choice accuracy across cue durations using age and training session as factors. The results indicated a main effect of cue duration $\left(F_{(4,700)}=388.54\right.$, $p<0.0001)$ with a decline in choice accuracy for shorter cue durations, an effect of age $\left(F_{(1,175)}=22.97, p<0.0001\right)$, and an interaction of age and cue duration $\left(F_{(4,700)}=39.90, p<0.0001\right)$. A main effect of training session was not observed and no interaction of session with age or cue duration could be observed. Due 
to the absence of an effect of training session, the data for each animal was averaged across the five test sessions and the averages used for illustration of the effects of age and cue duration (Fig. 2). Post hoc analysis revealed that at the $30 \mathrm{~s}$ time point, middle-age rats performed slightly, yet significantly, better than young controls; however, at the shortest cue durations $(0.5$ and $0.25 \mathrm{~s})$, middle-age animals exhibited a decrease in choice accuracy (Fig. 2A).

Examination of the percentage of omissions (Fig. $2 B$ ) indicated main effects of cue duration $\left(F_{(4,700)}=181.29, p<\right.$ $0.0001)$ and age $\left(F_{(1,175)}=42.76, p<\right.$ $0.0001)$, and an interaction of age and cue duration $\left(F_{(4,700)}=27.38, p<0.0001\right)$. Again, no effect of training session was observed and training session did not interact with age or cue duration. Consistent with an increase in attentional requirement, omissions increased as the cue duration decreased. Post hoc tests performed for each cue duration, averaged across training sessions for each animal, indicated that middle-age rats exhibited a higher percentage of omissions at four of the cue intervals $(30,2.5,0.5$, and $0.25 \mathrm{~s})$, and there was a trend $(p=0.054)$ for an age-related increase in omissions at the $10 \mathrm{~s}$ cue interval.

Figure $2 C$ illustrates the percentage of premature responses (i.e., a response during the intertrial interval, before the presentation of the cue stimulus). An ANOVA indicated a tendency $(p=0.06)$ for an effect of session in the absence of an age by session interaction. Post hoc analysis within each age group indicated no effect of training session. In contrast, a main effect of age $\left(F_{(1,175)}=36.97, p<0.0001\right)$ was observed for premature responses. Interestingly, middle-age animals maintain a lower percentage of premature responses compared with young, indicative of spared or even enhanced inhibitory response control. Last, an age difference was observed in the behavioral measure of choice latency $\left(F_{(1,175)}=40.61, p<0.001\right)$ in the absence of an effect of training session, with middle-age rats requiring more time to make a correct response (Fig. 2D). The decrease in choice accuracy and increase in omissions and choice latency indicate that middle-age rats exhibit impaired executive function relative to young adults.

To examine the specificity of the age-related differences in performance, measures of motor function (magazine latency) and motivation (number of initiated trials) were examined. No effect of session was observed for magazine latency and number of initiated trials. Furthermore, no age-related difference was observed for measures of time required to collect the food reward once dispensed (Fig. 3A) or the average number of initiated trials (Fig. 3B). As suggested by past studies using the 5-CSRTT (Pas-

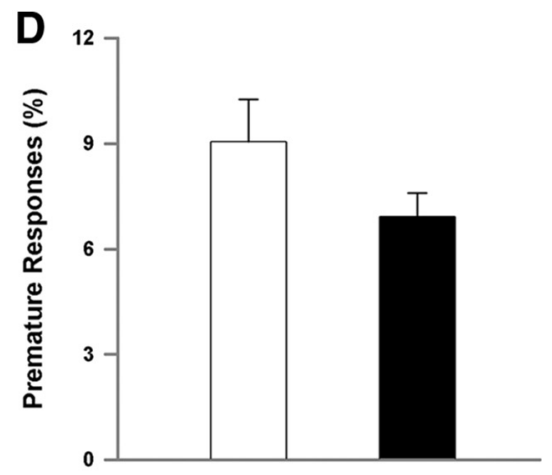

E
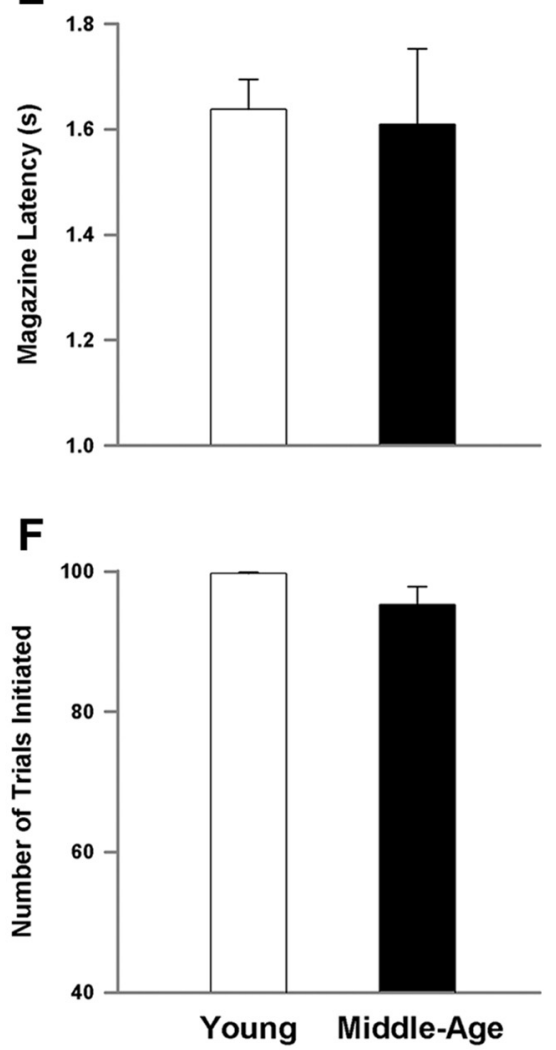

Figure 4. Age-related differences in performance of the 5-CSRTT are not due to sensory deficits. The cue duration was held at $0.5 \mathrm{~s}$ and the illumination intensity was varied from full to one-third of full. Varying the cue intensity does not affect choice accuracy $(\boldsymbol{A})$, the percentage of omissions $(\boldsymbol{B})$, or choice latency $(\boldsymbol{C})$, while an effect of age is still present. $\boldsymbol{D}$, Percentage of premature responses decreases with age. No age difference was observed for magazine latency $(\boldsymbol{E})$ or the number of initiated trials $(\boldsymbol{F})$.

setti et al., 2002; Chudasama et al., 2003), a lack of a difference in the magazine latency and average number of initiated trials suggests similar motor function and motivational dynamics, respectively.

Performance in the variable cue intensity paradigm

Apart from decreased mobility or lack of motivation to perform the task, middle-age rats may be impaired in their ability to visually perceive the cue stimulus. Therefore, the cue duration was set to $0.5 \mathrm{~s}$ and the ability to detect the visual cue stimulus was tested over $3 \mathrm{~d}$ for the middle-age and young animals using the variable cue intensity paradigm (Fig. 4). For all behavioral measures, the main effect of training session and age by training session interactions were not significant. Due to the absence of an effect of 
A
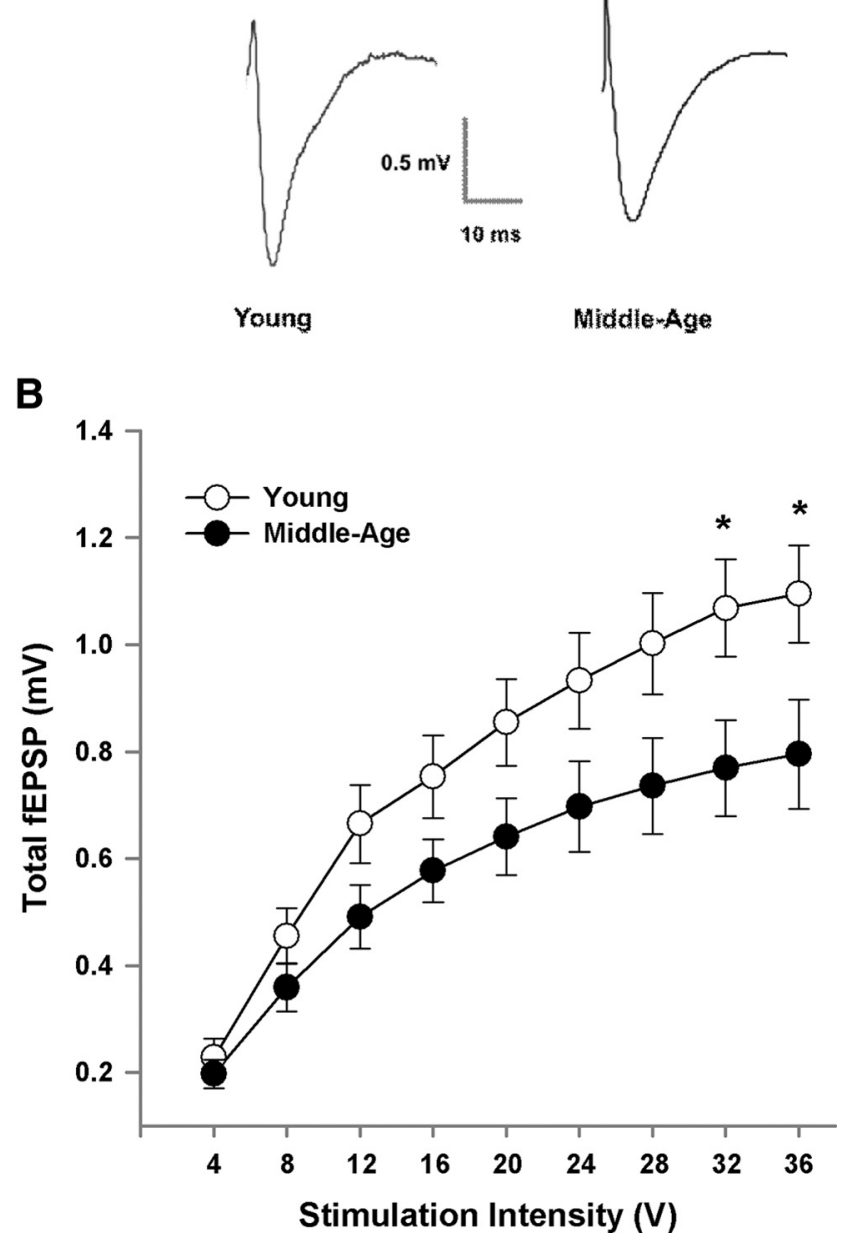

Figure 5. Decrease in synaptic strength in middle-age animals. $\boldsymbol{A}$, Examples of the totalfEPSP recorded in the $\mathrm{MPFC}$ from young and middle-age animals. $\boldsymbol{B}$, Input- output curves of the total-fEPSP for young ( $n=32 / 10$ slices/animals) and middle-age animals ( $n=29 / 16$ slices/ animals), plotting the mean \pm SEM amplitude across animals, relative to stimulation intensity. Asterisk indicates a significant age difference $(p<0.05)$.

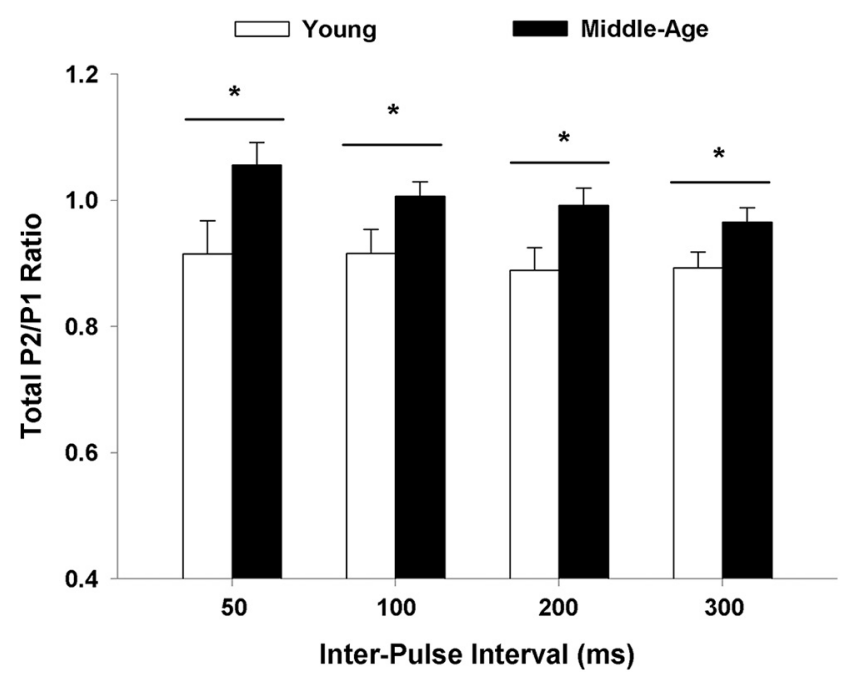

Figure 6. The paired-pulse response is increased in middle-age. The paired-pulse ratios for slices were averaged within each animal (young: 19/10 slices/animals; middle-age: $25 / 16$ slices/animals) and the mean + SEM the total-fEPSP paired-pulse ratio is provided for paired-pulse intervals from 50 to $300 \mathrm{~ms}$. Asterisk indicates a significant age difference $(p<0.05)$.
A

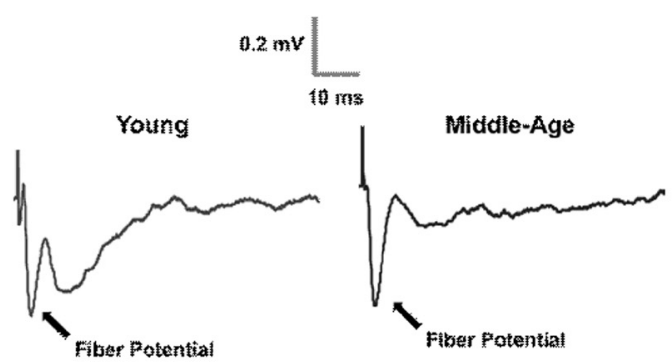

B

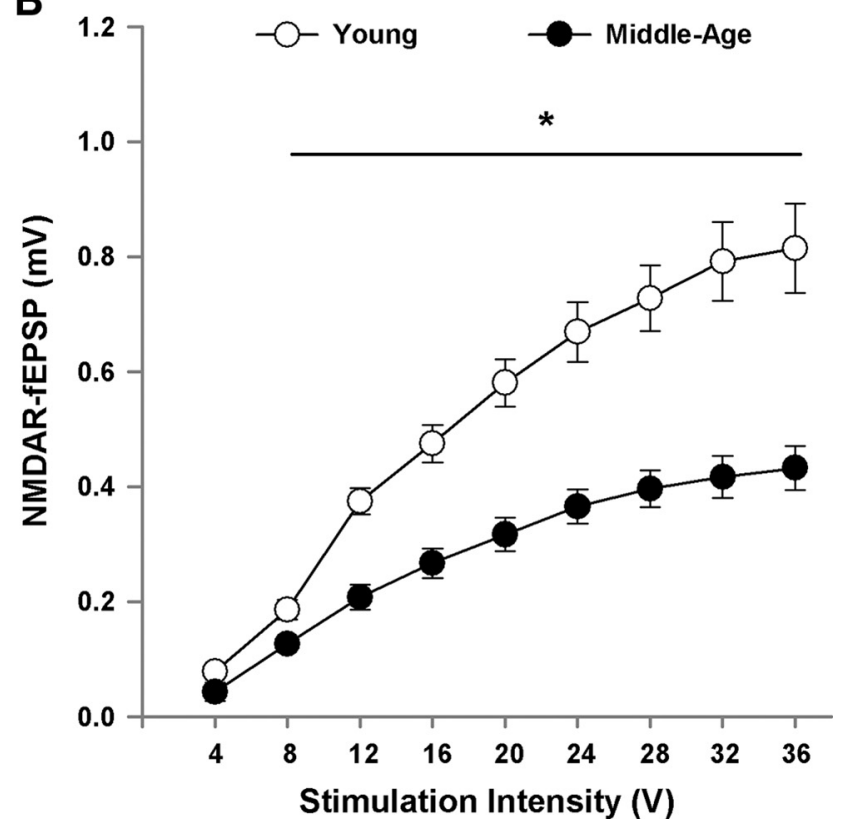

Figure 7. Decrease in the NMDAR-mediated synaptic response in middle-age animals. $\boldsymbol{A}$, Examples of the NMDAR-fEPSP recorded in the MPFC from young and middle-age animals. $\boldsymbol{B}$, Input- output curves plotting the mean \pm SEM amplitude of the NMDAR-fEPSP relative to stimulation intensity for young ( $n=23 / 9$ slices/animals) and middle-age animals ( $n=29 / 16$ slices/animals). Asterisk indicates a significant age difference $(p<0.05)$.

training session, the data were averaged across the three test sessions for each animal and the means for the animals were used for illustration of the effects of age and cue intensity. No effect of cue intensity and no age by cue intensity interaction were observed, indicating that reducing the brightness of the visual stimulus did not disrupt attentional or executive performance (Fig. $4 A-C$ ). An age-related decrease in choice accuracy $\left(F_{(1,105)}=5.88, p<0.05\right.$; Fig. $4 A)$, increase in percentage of omissions $\left(F_{(1,105)}=10.57, p<0.005\right.$; Fig. $4 B)$, increase in choice latency $\left(F_{(1,105)}=32.16, p<0.0001\right)$, and decrease in premature responses $\left(F_{(1,105)}=7.53, p<0.01\right.$; Fig. $\left.4 D\right)$ was confirmed. Similarly, there was no age-related difference in the measure of magazine latency (Fig. $4 E$ ) or the average number of initiated trials (Fig. 4F). Taken collectively, the data are consistent with the conclusion that the emergence of impaired performance in middle-age animals was due to a decline in attentional processes and not due to sensorimotor function.

Electrophysiology of senescent synapses in the mPFC

To examine possible alterations in glutamatergic synaptic transmission, total fEPSPs (total-fEPSPs) were recorded from the mPFC. An input-output curve was generated by plotting the amplitude of total synaptic response from middle-age $(n=$ $29 / 16$ slices/animals) and young $(n=32 / 10$ slices/animals $)$ as 
a function of increasing stimulation intensity (Fig. 5). The responses at each intensity were averaged across slices within each animal for analysis and a repeated-measures ANOVA indicated main effects of increasing stimulation intensity $\left(F_{(8,192)}=135.05, p<0.0001\right)$ and a tendency for an age effect $(p=$ 0.06). A significant age by stimulation intensity interaction was observed $\left(F_{(8,192)}=5.52, p<0.0001\right)$ and post hoc analyses for each stimulus intensity indicated that the response was increased in young animals for the highest stimulation intensities (Fig. 5B).

To determine whether alterations in presynaptic function contributed to the differences in synaptic transmission, paired-pulse analysis of the total synaptic response was conducted in $\mathrm{mPFC}$ slices (middle-age: 25/16 slices/animals; young: $19 / 10$ slices/animals). The first pulse was set to elicit $\sim 50 \%$ of the maximal fEPSP response and pulse pairs were delivered at varying interpulse intervals. The pairedpulse ratios for slices were averaged within each animal and the analysis was conducted across animals. The response from young animals exhibited a paired-pulse depression (a paired-pulse ratio $<1$ ) for each interval (Fig. 6). For older animals, paired-pulse depression was only observed for the 200-300 ms intervals. An ANOVA across stimulation intensities indicated an effect of age $\left(F_{(1,72)}=4.41\right.$, $p<0.05)$ and paired-pulse interval $\left(F_{(3,72)}=\right.$ $4.33, p<0.01)$ in the absence of an interaction. The age effect was due to a smaller paired-pulse ratio in young animals, which was observed for every paired-pulse interval (Fig. 6). Post hoc analysis on the influence of pulse interval indicated that the amplitude of the second response decreased with an increase in the paired-pulse interval such that the ratio was reduced for the 200 and $300 \mathrm{~ms}$, relative to the $50 \mathrm{~ms}$ interval. Examination of the interval effects in each age group indicated that this effect was only observed in slices from older animals $\left(F_{(3,45)}=5.52, p<0.005\right)$.

Following the assessment of the total synaptic response, the NMDAR component of the synaptic response was pharmacologically isolated. Input-output curves were constructed and the synaptic response at each intensity was averaged across slices from the same animal (middle-age: $n=29 / 16$ slices/animals; young: $n=23 / 9$ slices/animals). A decrease in the NMDAR synaptic response was observed for input-output curves plotting the NMDAR-fEPSPs amplitude as a factor of increasing stimulation intensity (Fig. 7). The age-related decrease was confirmed by a repeated-measures ANOVA, which indicated a significant main effect of stimulus intensity $\left(F_{(8,184)}=197.76, p<0.0001\right)$ and age $\left(F_{(1,23)}=30.26\right.$, $p<0.0001)$. Furthermore, an age by stimulation intensity interaction was observed $\left(F_{(8,184)}=19.98, p<0.0001\right)$ and post hoc analyses localized age-related differences in NMDAR responses to an increase in responses for young, relative to middle-age.

\section{Redox regulation of NMDAR function}

To determine whether a decline in the NMDAR response in middle-age was due to redox state, NMDAR responses in the $\mathrm{mPFC}$ were isolated and the reducing agent DTT $(0.5 \mathrm{~mm})$ was applied to slices obtained from young and middle-age rats. For the subset of young $(n=10 / 8$ slices/animals) and middle-age $(n=$ $17 / 15$ slices/animals) animals that were examined, the NMDARfEPSP amplitude was maintained at $\sim 50 \%$ of maximum and a stable baseline was recorded for at least $10 \mathrm{~min}$. Subsequent application of DTT resulted in a marked increase in the synaptic response from the baseline for both young $(p<0.005)$ and middle-age $(p<0.0001)$ animals (Fig. 8). However, the bath application of DTT increased the NMDAR-fEPSP to a greater extent $\left(F_{(1,25)}=5.0, p<0.05\right)$ in middle-age rats $(143.05 \pm$ $7.6 \%)$ compared with young animals $(119.23 \pm 4.79 \%)$ indicating age-related redox regulation of NMDAR function in the mPFC.

\section{Western blot analysis}

Biochemical protein analysis was performed to determine whether the decrease in NMDAR function with advancing age is mediated by decreased expression of NMDAR-related proteins. The mPFC from a subset of behaviorally characterized young 
A

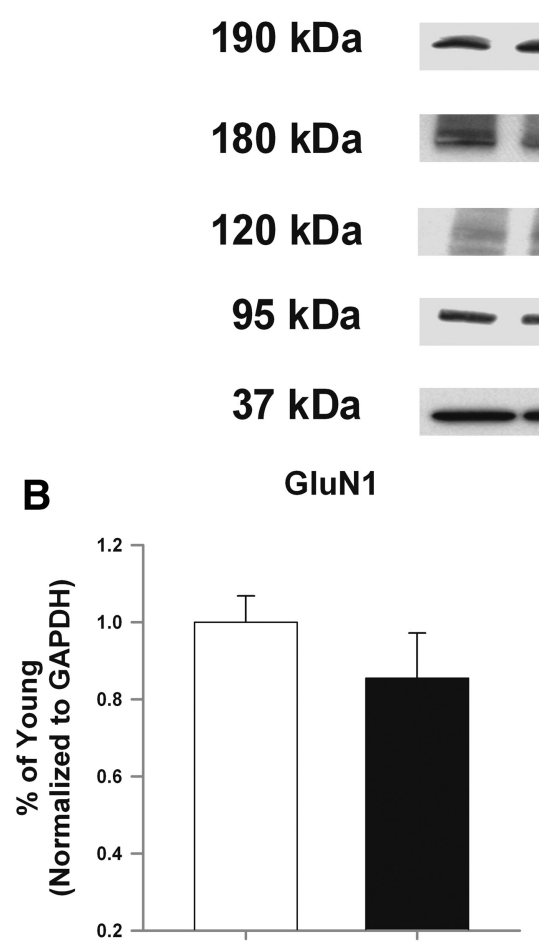

D

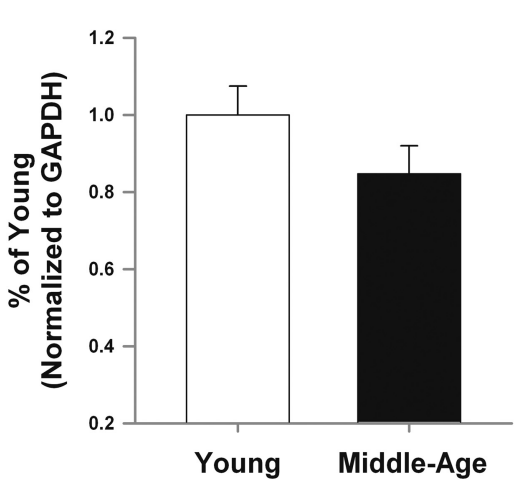

GluN2B

GluN2A

GluN1

PSD95

GAPDH
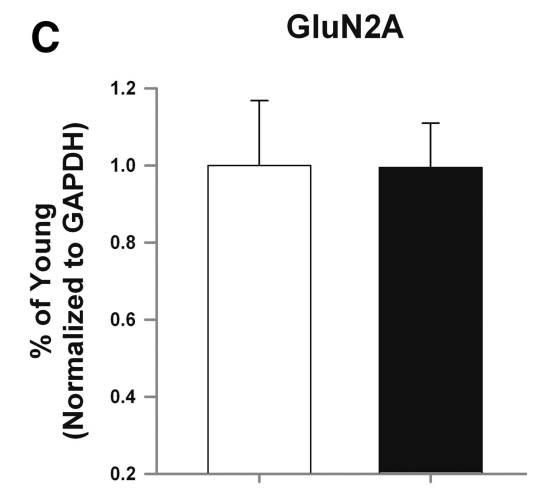

E

PSD-95

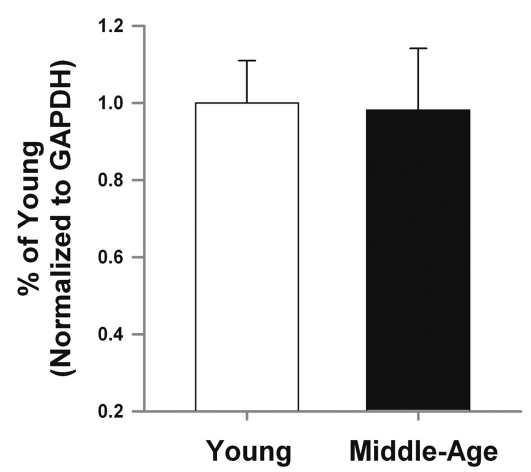

Figure 9. Aging is not associated with a marked change in NMDAR subunits examined in mPFC lysates from young and middle-age rats. $\boldsymbol{A}$, Examples of Western blots for the proteins examined. For quantification, band intensities were normalized to the expression of GAPDH and this value was normalized to the mean value of young from the same blot and plotted for GluN1 (B), GluN2A (C), GluN2B (D), and PSD-95 (E).

Table 2. Regression analyses of behavior and synaptic function

\begin{tabular}{|c|c|c|c|c|c|c|c|c|}
\hline & \multicolumn{2}{|c|}{ Choice accuracy } & \multicolumn{2}{|c|}{$\begin{array}{l}\text { Percent } \\
\text { omissions }\end{array}$} & \multicolumn{2}{|c|}{ Choice latency } & \multicolumn{2}{|c|}{$\begin{array}{l}\text { Premature } \\
\text { responses }\end{array}$} \\
\hline & $R^{2}$ & $p$ value & $R^{2}$ & $p$ value & $R^{2}$ & $p$ value & $R^{2}$ & $p$ value \\
\hline Total-fEPSP & 0.337 & 0.005 & 0.246 & 0.05 & 0.24 & 0.05 & & NS \\
\hline Middle-age & 0.268 & 0.05 & & NS & & NS & & \\
\hline $\begin{array}{l}\text { Paired-pulse } \\
\text { Middle-age }\end{array}$ & & NS & & NS & & NS & & NS \\
\hline NMDAR-fEPSP & 0.427 & 0.0005 & 0.33 & 0.005 & 0.32 & 0.005 & & NS \\
\hline Middle-age & 0.277 & 0.05 & & NS & & NS & & \\
\hline DTT growth & & NS & 0.273 & 0.05 & 0.27 & 0.05 & & NS \\
\hline Middle-age & & & & NS & 0.24 & 0.076 & & \\
\hline GluN2B expression & 0.339 & 0.05 & & NS & & NS & & NS \\
\hline Middle-age & 0.447 & 0.05 & & & & & & \\
\hline
\end{tabular}

$(n=8)$ and middle-age $(n=9)$ rats was collected and processed for Western blots. No significant age difference was observed in the measure of optical density (normalized to GAPDH loading control) for any of the synaptic proteins (GluN1, GluN2A, GluN2B, and PSD-95) that were assessed (Fig. 9), although there was a tendency $(p=0.1)$ for an age-related decrease in expression of the GluN2B subunit of the NMDAR.

Regression analysis of behavior and senescent mPFC synaptic function Regression analyses were performed to determine whether the decrease in glutamatergic transmission and NMDAR function were associated with impaired performance on the 5-CSRTT. Choice latency and premature responses across all trials were used as measures of information processing and response inhibition, respectively. In addition, choice accuracy and percentage of omissions from the $0.25 \mathrm{~s}$ cue duration time point were used, as this was the time point where attentional abilities were the most taxed as well as where the largest differences were observed between young and middle-age rats. Table 2 provides the $R^{2}$ and $p$ values for significant regressions. If a significant regression was observed across all animals, a subsequent regression was performed to determine whether the relationship held for middle-age animals. Interestingly, measures of synaptic function did not correlate with premature responses. Furthermore, the paired-pulse ratio for the $50 \mathrm{~ms}$ interpulse interval did not correlate with any of the behavioral measures. The total-fEPSP and NMDAR-fEPSP were averaged across the last three stimulation intensities $(28,32$, and $36 \mathrm{~V}$ ) and used as a measure of glutamatergic transmission and NMDAR function, respectively. Across all animals, significant correlations were observed for the averaged total-fEPSP and averaged NMDAR-fEPSP when compared with choice accuracy, percentage of omissions, and choice latency. In middle-age animals, the correlations were maintained between choice accuracy and the totalfEPSP and NMDAR-fEPSP (Fig. 10A,B). Across all animals, the percentage of omissions and choice latency was correlated with the change in NMDAR response, as a result of DTT bath application, and there was a tendency ( $p=0.076)$ for the DTT-induced response to correlate with choice latency, when the regression was limited to middle-age (Fig. 10C). Finally, expression of the GluN2B subunit was correlated with choice accuracy across all animals and in the middle-age subgroup (Fig. 10D).

\section{Discussion}

Impaired attention

Aging in many species is associated with impairments in episodic memory and executive function. The current study emphasizes 
that impaired executive function, specifically attentional deficits, are observed in middle-age indicating that at least for rodent models of aging, impaired attention is an early marker of cognitive decline. Impaired executive function was observed as an age-related increase in choice latency. The increase in choice latency was not associated with a concomitant increase in magazine latency indicating that the difference was specific for cognitive processing rather than a simple motor deficit. Both age groups exhibited an increase in omissions and a decrease in choice accuracy for shorter cue durations, when attentional load increases. Again, attentional deficits were observed as an age-related difference in omissions and choice accuracy for short cue durations. Previous studies have suggested that an increase in the percentage of omissions is an indication of impaired attention resulting in detection failures (Jones et al., 1995; Harati et al., 2011). Performance was not differentially affected by reducing the brightness of the visual cue, indicating that the difference was not due to impaired visual sensory processing. Furthermore, it is unlikely that the increase in omissions reflects reduced motivation toward the food reward since the average number of initiated trials was not different between the two age groups, suggesting similar motivation levels (Passetti et al., 2002). Finally, middle-age animals exhibited slower learning during the acquisition phase of training; however, this does not explain the attentional differences, as there was no indication of improved performance on any of the behavioral variables over the $5 \mathrm{~d}$ of testing.

\section{Inhibitory response control}

In contrast to measures of attention, the percentage of premature responses, a measure of inhibitory response control, was reduced in middle-age rats compared with young. Similar findings were previously reported, in that either no effect of age or even an enhanced ability to withhold a prepotent motor response with age was observed (Jones et al., 1995; Muir et al., 1999; Harati et al., 2011). The results suggest that the various aspects of executive function are differentially sensitive to age-related impairment. Indeed, attention, response inhibition, attentional set-shifting, and working memory are thought to involve different brain systems interacting with distinct prefrontal circuits (Dalley et al., 2004).

\section{Electrophysiology of senescent synapses in the mPFC}

Pharmacological studies suggest that NMDARs are involved in executive processes (Stefani and Moghaddam, 2005; Cui et al., 2011; Dalton et al., 2011; Arnsten et al., 2012; Carli and Invernizzi, 2014). Similarly, anatomical studies indicate that there is an age-related loss of thin dendritic spines in the PFC of impaired animals (Bourne and Harris, 2007; Morrison and Baxter, 2012). The thin spines are thought to be involved in NMDAR-
B
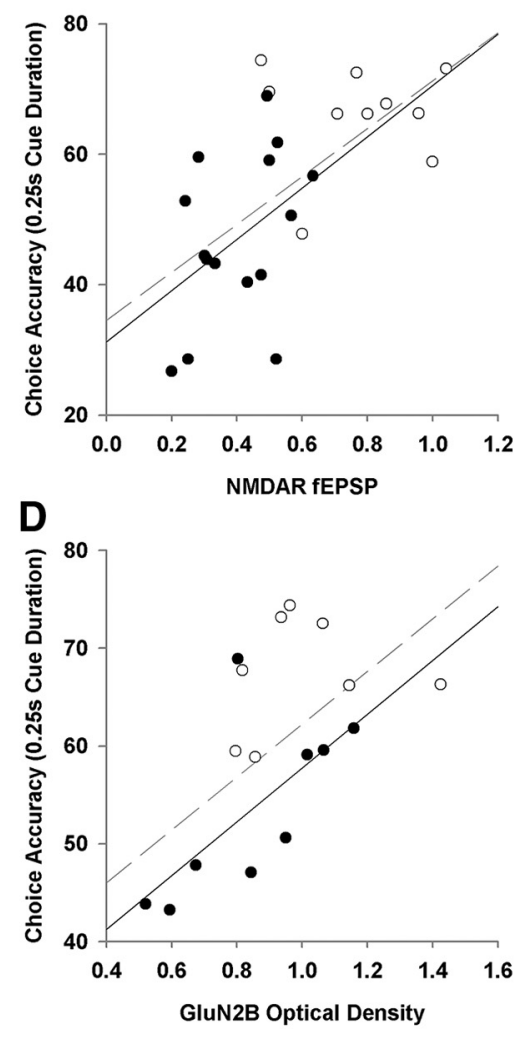

Figure 10. Relationship between behavior and synaptic function. Individual measures are shown for young (open circles) and 作 cue duration) was associated with reduced synaptic transmission measured as $(\boldsymbol{A})$ the total-fEPSP and $(\boldsymbol{B})$ the NMDAR-fEPSP and $(\boldsymbol{D})$ a decrease in the expression of the GluN2B subunit expression. (C) Longer choice latencies were associated with larger DTT-induced increase in the NMDAR synaptic response.

mediated synaptic plasticity, suggesting a possible decrease in NMDAR-mediated synaptic transmission contributes to agerelated impairments in executive function. In contrast, biochemical studies related to the expression and binding of glutamate receptors have had mixed results with regard to aging and cognition (Piggott et al., 1992; Mitchell and Anderson, 1998; Migani et al., 2000; Nicolle and Baxter, 2003; Liu et al., 2008; Majdi et al., 2009). In the current study, we observed evidence that the totalfEPSP, which is largely due to activation of AMPA glutamate receptors, exhibits a modest decrease in middle-age compared with young adult. The reduction in the total-fEPSP may be due in part to inhibition of transmitter release. Normally, cortical synapses exhibit paired-pulse depression, which may reflect an initially high probability of transmitter release (Castro-Alamancos and Connors, 1997; Hempel et al., 2000). Indeed, we observed paired-pulse depression in young animals, which shifted to paired-pulse facilitation in middle-age. A similar age-related shift in paired-pulse responses has been described for other cortices (David-Jurgens and Dinse, 2010; Schmidt et al., 2010). Electrophysiological measures of the frequency of spontaneous synaptic responses indicate a marked increase in inhibitory tone and either a decrease or no change in AMPA receptor-mediated responses in the PFC of impaired animals ( $\mathrm{Lu}-$ ebke et al., 2004; Bories et al., 2013). Thus, it is possible that an increase in GABAergic inhibitory tone over the course of aging acts to decrease basal presynaptic release resulting in a shift from pairedpulse depression to paired-pulse facilitation (Chu and Hablitz, 2003). 
In contrast to the relatively mild decrease in the total-fEPSP, middle-age was associated with a striking decrease in the NMDAR-mediated synaptic response. The decrease in the NMDAR-fEPSP may be due to a combination of factors including decreased transmitter release and a decrease in the expression of NMDAR subunits. Previous work has provided evidence for a decrease in GluN2B expression with advanced age (Bai et al., 2004; Zhao et al., 2009). In the current study, we observed a tendency for a decrease in the GluN2B subunit. It is possible that the decrease may progress with more advanced ages. Unfortunately, due to the relatively low resolution for localizing receptor changes, the Western blot results do not necessarily reflect synaptic NMDARs. Importantly, NMDARs are thought to localize mainly to thin dendritic spines and a loss of thin spines is observed in the prelimbic cortex of middle-age rats (Bloss et al., 2011), suggesting that the observed loss on NMDARs may reflect the loss of thin spines.

Recent work indicates that an oxidized redox state mediates senescent neurophysiology in the hippocampus, including an increase in the afterhyperpolarization, decreased cell excitability, and a decrease in NMDAR function, including impaired synaptic plasticity (Bodhinathan et al., 2010a, b; Foster, 2012b). Importantly, the onset of impaired episodic memory in middle-age is associated with a redox-mediated decline in NMDAR function and treatments that promoted excess hydrogen peroxide resulted in an aging phenotype, with impaired cognition and a reduction in the NMDAR-mediated component of synaptic transmission (Lee et al., 2012, 2014; Kumar and Foster, 2013). Hydrogen peroxide influences NMDAR function by inducing disulfide bonds between cysteine residues on proteins that impact NMDAR function (Bodhinathan et al., 2010b). The disulfide linkages can subsequently be reduced to free thiols by DTT to increase synaptic NMDAR responses. Normally, hydrogen peroxide is converted to water and oxygen by catalase or glutathione peroxidase. Previous work suggests that aging is associated with a decrease in catalase activity in the PFC (Clark et al., 1992; Ciriolo et al., 1997), which could result in a more oxidized redox environment (Lee et al., 2014). In the current study, bath application of DTT increased the NMDAR-fEPSP to a greater extent in middle-age animals. This finding indicates that the middle-age mPFC is associated with a more oxidized redox state, which contributes to the marked functional decrease in NMDARs. An interaction of redox state and NMDAR hypofunction is thought to contribute to mental disorders such as schizophrenia (Steullet et al., 2006; Snyder and Gao, 2013; X. Wang et al., 2013). The finding that decreased mPFC NMDAR-fEPSP and redox regulation of the NMDAR synaptic responses correlated with behavioral measures of attention suggests that redox-mediated weakening of NMDAR function contributes to an age-related decline in cognitive processes that depend on this brain region.

\section{Relationship between glutamate synaptic transmission and executive function during aging}

Variability in attention for middle-age animals was correlated with a decline in glutamate transmission measured as a decrease in the total-fEPSP and NMDAR-fEPSP. In terms of potential mechanisms that contribute to decreased NMDAR function and impaired cognition, choice accuracy was correlated with GluN2B expression and choice latency showed a trend for a relationship with measures of redox-mediated inhibition of NMDAR function. As noted above, the decline in NMDAR function may be involved in the loss of thin spines on pyramidal cells observed in aged cognitively impaired monkeys (Bourne and Harris, 2007;
Bloss et al., 2011; Morrison and Baxter, 2012). However, it should be noted that the location of the NMDAR impairment with regard to spines or cell type cannot be determined from the current study. In addition to NMDAR regulation of pyramidal cell firing during performance of an executive task (M. Wang et al., 2013), there is evidence that NMDAR blockade results in disinhibition, increasing neural activity and the release of glutamate (Moghaddam et al., 1997; Jackson et al., 2004), possibly by reducing NMDAR activity on inhibitory interneurons (Povysheva and Johnson, 2012). A differential reduction in NMDAR function in pyramidal cells and interneurons might be expected to shift the balance of excitation/inhibition to disrupt the PFC circuits.

In summary, we found that attention deficits were apparent in middle-age animals. Additionally, middle-age was characterized by a decrease in glutamatergic transmission in the mPFC. In particular, a robust decrease in NMDAR-mediated synaptic responses was correlated with several measures of attention. In turn, the decrease in NMDAR function is the result of an altered redox state. Together with previous work indicating that an oxidize redox state mediates senescent neurophysiology in the hippocampus (Bodhinathan et al., 2010a, b; Kumar and Foster, 2013; Lee et al., 2014), the results point to redox state changes as a process that contributes to the vulnerability of brain regions involved in age-related cognitive decline.

\section{References}

Alexander GE, Ryan L, Bowers D, Foster TC, Bizon JL, Geldmacher DS, Glisky EL (2012) Characterizing cognitive aging in humans with links to animal models. Front Aging Neurosci 4:21. CrossRef Medline

Arnsten AF, Wang MJ, Paspalas CD (2012) Neuromodulation of thought: flexibilities and vulnerabilities in prefrontal cortical network synapses. Neuron 76:223-239. CrossRef Medline

Babcock RL, Salthouse TA (1990) Effects of increased processing demands on age differences in working memory. Psychol Aging 5:421-428. CrossRef Medline

Bai L, Hof PR, Standaert DG, Xing Y, Nelson SE, Young AB, Magnusson KR (2004) Changes in the expression of the NR2B subunit during aging in macaque monkeys. Neurobiol Aging 25:201-208. CrossRef Medline

Bañuelos C, Beas BS, McQuail JA, Gilbert RJ, Frazier CJ, Setlow B, Bizon JL (2014) Prefrontal cortical GABAergic dysfunction contributes to agerelated working memory impairment. J Neurosci 34:3457-3466. CrossRef Medline

Barense MD, Fox MT, Baxter MG (2002) Aged rats are impaired on an attentional set-shifting task sensitive to medial frontal cortex damage in young rats. Learn Mem 9:191-201. CrossRef Medline

Beas BS, Setlow B, Bizon JL (2013) Distinct manifestations of executive dysfunction in aged rats. Neurobiol Aging 34:2164-2174. CrossRef Medline

Birrell JM, Brown VJ (2000) Medial frontal cortex mediates perceptual attentional set shifting in the rat. J Neurosci 20:4320-4324. Medline

Bizon JL, Foster TC, Alexander GE, Glisky EL (2012) Characterizing cognitive aging of working memory and executive function in animal models. Front Aging Neurosci 4:19. CrossRef Medline

Bloss EB, Janssen WG, Ohm DT, Yuk FJ, Wadsworth S, Saardi KM, McEwen BS, Morrison JH (2011) Evidence for reduced experience-dependent dendritic spine plasticity in the aging prefrontal cortex. J Neurosci 31: 7831-7839. CrossRef Medline

Bodhinathan K, Kumar A, Foster TC (2010a) Redox sensitive calcium stores underlie enhanced after hyperpolarization of aged neurons: role for ryanodine receptor mediated calcium signaling. J Neurophysiol 104:25862593. CrossRef Medline

Bodhinathan K, Kumar A, Foster TC (2010b) Intracellular redox state alters NMDA receptor response during aging through $\mathrm{Ca} 2+/$ calmodulindependent protein kinase II. J Neurosci 30:1914-1924. CrossRef Medline

Bories C, Husson Z, Guitton MJ, De Koninck Y (2013) Differential balance of prefrontal synaptic activity in successful versus unsuccessful cognitive aging. J Neurosci 33:1344-1356. CrossRef Medline

Bourne J, Harris KM (2007) Do thin spines learn to be mushroom spines that remember? Curr Opin Neurobiol 17:381-386. CrossRef Medline

Carli M, Invernizzi RW (2014) Serotoninergic and dopaminergic modula- 
tion of cortico-striatal circuit in executive and attention deficits induced by NMDA receptor hypofunction in the 5 -choice serial reaction time task. Front Neural Circuits 8:58. CrossRef Medline

Carli M, Robbins TW, Evenden JL, Everitt BJ (1983) Effects of lesions to ascending noradrenergic neurones on performance of a 5-choice serial reaction task in rats; implications for theories of dorsal noradrenergic bundle function based on selective attention and arousal. Behav Brain Res 9:361-380. CrossRef Medline

Castro-Alamancos MA, Connors BW (1997) Distinct forms of short-term plasticity at excitatory synapses of hippocampus and neocortex. Proc Natl Acad Sci U S A 94:4161-4166. CrossRef Medline

Chu Z, Hablitz JJ (2003) GABA(B) receptor-mediated heterosynaptic depression of excitatory synaptic transmission in rat frontal neocortex. Brain Res 959:39-49. CrossRef Medline

Chudasama Y, Passetti F, Rhodes SE, Lopian D, Desai A, Robbins TW (2003) Dissociable aspects of performance on the 5-choice serial reaction time task following lesions of the dorsal anterior cingulate, infralimbic and orbitofrontal cortex in the rat: differential effects on selectivity, impulsivity and compulsivity. Behav Brain Res 146:105-119. CrossRef Medline

Ciriolo MR, Marasco MR, Iannone M, Nisticò G, Rotilio G (1997) Decrease of immunoreactive catalase protein in specific areas of ageing rat brain. Neurosci Lett 228:21-24. CrossRef Medline

Clark AS, Magnusson KR, Cotman CW (1992) In vitro autoradiography of hippocampal excitatory amino acid binding in aged Fischer 344 rats: relationship to performance on the Morris water maze. Behav Neurosci 106:324-335. CrossRef Medline

Cui Y, Jin J, Zhang X, Xu H, Yang L, Du D, Zeng Q, Tsien JZ, Yu H, Cao X (2011) Forebrain NR2B overexpression facilitating the prefrontal cortex long-term potentiation and enhancing working memory function in mice. PLoS One 6:e20312. CrossRef Medline

Dalley JW, McGaughy J, O'Connell MT, Cardinal RN, Levita L, Robbins TW (2001) Distinct changes in cortical acetylcholine and noradrenaline efflux during contingent and noncontingent performance of a visual attentional task. J Neurosci 21:4908-4914. Medline

Dalley JW, Theobald DE, Bouger P, Chudasama Y, Cardinal RN, Robbins TW (2004) Cortical cholinergic function and deficits in visual attentional performance in rats following $192 \mathrm{IgG}$-saporin-induced lesions of the medial prefrontal cortex. Cereb Cortex 14:922-932. CrossRef Medline

Dalton GL, Ma LM, Phillips AG, Floresco SB (2011) Blockade of NMDA GluN2B receptors selectively impairs behavioral flexibility but not initial discrimination learning. Psychopharmacology 216:525-535. CrossRef Medline

David-Jürgens M, Dinse HR (2010) Effects of aging on paired-pulse behavior of rat somatosensory cortical neurons. Cereb Cortex 20:1208-1216. CrossRef Medline

Foster TC (2012a) Challenges and opportunities in characterizing cognitive aging across species. Front Aging Neurosci 4:33. CrossRef Medline

Foster TC (2012b) Dissecting the age-related decline on spatial learning and memory tasks in rodent models: N-methyl-D-aspartate receptors and voltage-dependent $\mathrm{Ca} 2+$ channels in senescent synaptic plasticity. Prog Neurobiol 96:283-303. CrossRef Medline

Gazzaley A, Cooney JW, Rissman J, D’Esposito M (2005) Top-down suppression deficit underlies working memory impairment in normal aging. Nat Neurosci 8:1298-1300. CrossRef Medline

Grottick AJ, Higgins GA (2002) Assessing a vigilance decrement in aged rats: effects of pre-feeding, task manipulation, and psychostimulants. Psychopharmacology 164:33-41. CrossRef Medline

Harati H, Majchrzak M, Cosquer B, Galani R, Kelche C, Cassel JC, Barbelivien A (2011) Attention and memory in aged rats: impact of lifelong environmental enrichment. Neurobiol Aging 32:718-736. CrossRef Medline

Hempel CM, Hartman KH, Wang XJ, Turrigiano GG, Nelson SB (2000) Multiple forms of short-term plasticity at excitatory synapses in rat medial prefrontal cortex. J Neurophysiol 83:3031-3041. Medline

Jackson ME, Homayoun H, Moghaddam B (2004) NMDA receptor hypofunction produces concomitant firing rate potentiation and burst activity reduction in the prefrontal cortex. Proc Natl Acad Sci U S A 101:84678472. CrossRef Medline

Jones DN, Barnes JC, Kirkby DL, Higgins GA (1995) Age-associated impairments in a test of attention: evidence for involvement of cholinergic systems. J Neurosci 15:7282-7292. Medline

Kumar A, Foster TC (2013) Linking redox regulation of NMDAR synaptic function to cognitive decline during aging. J Neurosci 33:15710-15715. CrossRef Medline

Kumar A, Foster TC (2014) Interaction of DHPG-LTD and synaptic-LTD at senescent CA3-CA1 hippocampal synapses. Hippocampus 24:466475. CrossRef Medline

Lee I, Kesner RP (2003) Time-dependent relationship between the dorsal hippocampus and the prefrontal cortex in spatial memory. J Neurosci 23:1517-1523. Medline

Lee WH, Kumar A, Rani A, Herrera J, Xu J, Someya S, Foster TC (2012) Influence of viral vector-mediated delivery of superoxide dismutase and catalase to the hippocampus on spatial learning and memory during aging. Antioxid Redox Signal 16:339-350. CrossRef Medline

Lee WH, Kumar A, Rani A, Foster TC (2014) Role of antioxidant enzymes in redox regulation of $\mathrm{N}$-methyl-D-aspartate receptor function and memory in middle-aged rats. Neurobiol Aging 35:1459-1468. CrossRef Medline

Liu P, Smith PF, Darlington CL (2008) Glutamate receptor subunits expression in memory-associated brain structures: regional variations and effects of aging. Synapse 62:834-841. CrossRef Medline

Luebke JI, Chang YM, Moore TL, Rosene DL (2004) Normal aging results in decreased synaptic excitation and increased synaptic inhibition of layer $2 / 3$ pyramidal cells in the monkey prefrontal cortex. Neuroscience 125 277-288. CrossRef Medline

Majdi M, Ribeiro-da-Silva A, Cuello AC (2009) Variations in excitatory and inhibitory postsynaptic protein content in rat cerebral cortex with respect to aging and cognitive status. Neuroscience 159:896-907. CrossRef Medline

Migani P, Magnone MC, Rossolini G, Piantanelli L (2000) Excitatory amino acid receptors in the prefrontal cortex of aging mice. Neurobiol Aging 21:607-612. CrossRef Medline

Mitchell JJ, Anderson KJ (1998) Age-related changes in [3H]MK-801 binding in the Fischer 344 rat brain. Neurobiol Aging 19:259-265. CrossRef Medline

Moghaddam B, Adams B, Verma A, Daly D (1997) Activation of glutamatergic neurotransmission by ketamine: a novel step in the pathway from NMDA receptor blockade to dopaminergic and cognitive disruptions associated with the prefrontal cortex. J Neurosci 17:2921-2927. Medline

Moore H, Dudchenko P, Bruno JP, Sarter M (1992) Toward modeling age-related changes of attentional abilities in rats: simple and choice reaction time tasks and vigilance. Neurobiol Aging 13:759-772. CrossRef Medline

Morrison JH, Baxter MG (2012) The ageing cortical synapse: hallmarks and implications for cognitive decline. Nat Rev Neurosci 13:240-250. CrossRef Medline

Muir JL, Everitt BJ, Robbins TW (1996) The cerebral cortex of the rat and visual attentional function: dissociable effects of mediofrontal, cingulate, anterior dorsolateral, and parietal cortex lesions on a five-choice serial reaction time task. Cereb Cortex 6:470-481. CrossRef Medline

Muir JL, Fischer W, Björklund A (1999) Decline in visual attention and spatial memory in aged rats. Neurobiol Aging 20:605-615. CrossRef Medline

Nicolle MM, Baxter MG (2003) Glutamate receptor binding in the frontal cortex and dorsal striatum of aged rats with impaired attentional setshifting. Eur J Neurosci 18:3335-3342. CrossRef Medline

Passetti F, Chudasama Y, Robbins TW (2002) The frontal cortex of the rat and visual attentional performance: dissociable functions of distinct medial prefrontal subregions. Cereb Cortex 12:1254-1268. CrossRef Medline

Paxinos G, Watson C (1986) The rat brain in stereotaxic coordinates. San Diego: Academic.

Piggott MA, Perry EK, Perry RH, Court JA (1992) [3H]MK-801 binding to the NMDA receptor complex, and its modulation in human frontal cortex during development and aging. Brain Res 588:277-286. CrossRef Medline

Povysheva NV, Johnson JW (2012) Tonic NMDA receptor-mediated current in prefrontal cortical pyramidal cells and fast-spiking interneurons. J Neurophysiol 107:2232-2243. CrossRef Medline

Robbins TW, James M, Owen AM, Sahakian BJ, Lawrence AD, McInnes L, Rabbitt PM (1998) A study of performance on tests from the CANTAB battery sensitive to frontal lobe dysfunction in a large sample of normal volunteers: implications for theories of executive functioning and cogni- 
tive aging. Cambridge Neuropsychological Test Automated Battery. J Int Neuropsychol Soc 4:474-490. CrossRef Medline

Samson RD, Barnes CA (2013) Impact of aging brain circuits on cognition. Eur J Neurosci 37:1903-1915. CrossRef Medline

Schmidt S, Redecker C, Bruehl C, Witte OW (2010) Age-related decline of functional inhibition in rat cortex. Neurobiol Aging 31:504-511. CrossRef Medline

Silver H, Goodman C, Bilker W (2009) Age in high-functioning healthy men is associated with nonlinear decline in some 'executive' functions in late middle age. Dement Geriatr Cogn Disord 27:292-300. CrossRef Medline

Snyder MA, Gao WJ (2013) NMDA hypofunction as a convergence point for progression and symptoms of schizophrenia. Front Cell Neurosci 7:31. CrossRef Medline

Staub B, Doignon-Camus N, Bacon E, Bonnefond A (2014) Investigating sustained attention ability in the elderly by using two different approaches: inhibiting ongoing behavior versus responding on rare occasions. Acta Psychol 146:51-57. CrossRef Medline

Stefani MR, Moghaddam B (2005) Systemic and prefrontal cortical NMDA receptor blockade differentially affect discrimination learning and setshift ability in rats. Behav Neurosci 119:420-428. CrossRef Medline

Stefani MR, Groth K, Moghaddam B (2003) Glutamate receptors in the rat medial prefrontal cortex regulate set-shifting ability. Behav Neurosci 117: 728-737. CrossRef Medline

Steullet P, Neijt HC, Cuénod M, Do KQ (2006) Synaptic plasticity impair- ment and hypofunction of NMDA receptors induced by glutathione deficit: relevance to schizophrenia. Neuroscience 137:807-819. CrossRef Medline

Tang LH, Aizenman E (1993a) Long-lasting modification of the N-methylD-aspartate receptor channel by a voltage-dependent sulfhydryl redox process. Mol Pharmacol 44:473-478. Medline

Tang LH, Aizenman E (1993b) The modulation of N-methyl-D-aspartate receptors by redox and alkylating reagents in rat cortical neurones in vitro. J Physiol 465:303-323. CrossRef Medline

Wang M, Yang Y, Wang CJ, Gamo NJ, Jin LE, Mazer JA, Morrison JH, Wang XJ, Arnsten AF (2013) NMDA receptors subserve persistent neuronal firing during working memory in dorsolateral prefrontal cortex. Neuron 77:736-749. CrossRef Medline

Wang X, Pinto-Duarte A, Sejnowski TJ, Behrens MM (2013) How Nox2containing NADPH oxidase affects cortical circuits in the NMDA receptor antagonist model of schizophrenia. Antioxid Redox Signal 18:1444-1462. CrossRef Medline

Zavagnin M, Borella E, De Beni R (2014) When the mind wanders: age-related differences between young and older adults. Acta Psychol 145:54-64. CrossRef Medline

Zhao X, Rosenke R, Kronemann D, Brim B, Das SR, Dunah AW, Magnusson KR (2009) The effects of aging on N-methyl-D-aspartate receptor subunits in the synaptic membrane and relationships to long-term spatial memory. Neuroscience 162:933-945. CrossRef Medline 